\title{
County Integrated Healthcare Organization, China Solution of Rural Health
}

\author{
Liya Wang1,2 \\ ${ }^{1}$ School of Public Affairs, University of Science and Technology of China, Hefei, China \\ ${ }^{2}$ Fundamental Department, Anhui Medical College, Hefei, China \\ Email: liyawang1013@qq.com
}

How to cite this paper: Wang, L. Y. (2017) County Integrated Healthcare Organization, China Solution of Rural Health. Chinese Studies, 6, 161-166. https://doi.org/10.4236/chnstd.2017.63015

Received: May 10, 2017

Accepted: June 23, 2017

Published: June 26, 2017

Copyright (c) 2017 by author and Scientific Research Publishing Inc. This work is licensed under the Creative Commons Attribution International License (CC BY 4.0).

http://creativecommons.org/licenses/by/4.0/

\begin{abstract}
"County Integrated Healthcare Organization" is a innovative solitary alliance of rural three-tier health service organization in recent China, led by a county hospital and composed of 2 - 3 township health centers and a number of village clinics under the township catchment respectively. It adopts insurance fund as financial leverage, vertically integrated the three-tier healthcare institutions. CIHO as a system focus on solving the existing problems, adopted the financial leverage of health insurance payment to promote the cooperation and formation of responsibility sharing, benefit sharing, promoting people health centered, win-win development among healthcare institutes in the county.
\end{abstract}

\section{Keywords}

Integrated Healthcare System, County, Rural Cooperative Medical System

\section{Case}

Zhao Hang, 33 years old, works in a barbershop with his wife in Hangzhou City, Zhejiang Province in China. He had hernia surgery guided by an expert from local leading hospital at his hometown health center, Tianchang County, Anhui Province. He returned home after the surgery and was taken care of by his parents for recovery, since the health center is not far away from the place they live. The total cost of this surgery was $2900 \mathrm{RMB}$, and Zhao paid only $640 \mathrm{RMB}$ out of pocket (Tobe et al., 2013). The same operation in the county hospital costs $4000 \mathrm{RMB}$, and the patient out of pocket payment (copayment) is $1200 \mathrm{RMB}$. Zhao received better and more complex medical services, but only paid the price of a township health center. What's more, the same operation will cost at least $6000 \mathrm{RMB}$ in his working city, with a copayment of more than $2400 \mathrm{RMB}$. In terms of total medical expenses, it costs Zhao no more than $800 \mathrm{RMB}$, including 
high-speed rail transportation fees, which is only $1 / 3$ of his working place.

In Anhui province of China, more and more local residents choose to go to their hometown for surgery and hospitalization, like Zhao Hang. This change is attributed to the reform of the County Integrated Healthcare Organization (CIHO), which is now occurring in Anhui province. The State Council recently issued a document to promote Anhui CIHO nationwide as one of the models of hospitals' alliances, thus pushing forward the tiered medical care.

\section{Description of County Integrated Healthcare Organization (CIHO)}

"County Integrated Healthcare Organization" (CIHO, similar to Integrated Delivery Systems in the US), is a solitary alliance of rural three-tier health service organizations, led by a county hospital and composed of 2 to 3 township health centers and a number of village clinics under the township jurisdiction. The New Rural Cooperative Medical System funds (NCMS), in accordance with the population in the catchment area, pay the alliance by a capitation-based global budget. The alliance is obliged to cover the deficit and retain the surplus within the given global budget. The cost of the residents' hospitalizations outside the county will be deducted from the global budget as well. This reform changed competition to cooperation amongst the members of CIHO, thus creating joint efforts to attract patients to be treated inside CIHO by improving quality of care. The share of copayments in terms of NCMS benefit policy is also adjusted to encourage patients seeking referral to county tertiary hospitals by the CIHO. There are two CIHO lead hospitals in each county on the average; the county hospital and the county traditional Chinese medicine hospital. Some counties may own a third lead hospital, usually a privately owned hospital. Started out with 15 counties in 2015 in Anhui province and expanded to 66 counties currently, the CIHO accounts for $90 \%$ of the agricultural counties' 49.14 million population. Each CIHO covers on average 200 - 300 thousand local residents average, north of Anhui province, which is densely populated and contains many more people.

$\mathrm{CIHO}$, which adopts insurance funding as financial leverage (Stuart \& Zacker, 1999), vertically integrates the three-tier healthcare institutions to deliver basic service according to its newly clarified functions. Village clinics are mainly engaged with the general outpatient visits, chronic disease management services, and referral services. Township health centers are mainly engaged in outpatient care and minor illness hospitalization, rehabilitation, the essential package of public health services, chronic disease management and referral services. County hospitals are mainly engaged with inpatient care, referral services to tertiary hospitals, clinical assistance and support to township health centers, and CIHO management.

CIHO reform has made the following progress: patients seek for service visits at village clinics first (used to jump to a higher level freely), two-way referral services are launched, and all institutions are accountable for respective duties. 
More and more patients receive their healthcare in nearby institutions. Inside the CIHO, it has reconstructed its medical services, for example, unification of the medical norms, resources (manpower, equipment, et.) deployment, performance evaluation, information systems, centralization of pharmacy and logistics service management. Telemedicine technology is widely applied in laboratory examination, DR and CT imaging, ECG and other diagnostic techniques. To guarantee the quality of medical care and medical cost containment, CIHO strictly enforce implementing clinical pathways plus case payments for inpatient care. Currently, nearly half of the inpatients are treated with clinical pathways, which is much higher than non-CIHO pilot counties.

Besides resources integration, doctors from CIHO members form $1+1+1$ family medicine teams, with a fixed linkage network communication using WeChat on mobile phones, patient referrals, chronic disease management, healthcare consulting and other methods. Team members with shared responsibility have enhanced the capacity and quality of healthcare. There are 396 family medicine teams in Tianchang which have greatly improved the status of village health personnel among the local residents, thereby improving the compliance rate of the medical advice given.

\section{Reform Background}

In 1950s and 1960s, the three-tier health network of rural China quickly solved the problem of lack of health manpower and medicine, eliminating severe infectious and endemic diseases (Hsiao, 1995). The Chinese average life expectancy has more than doubled since then. After a policy of reform and becoming more open, the Chinese government focused on developing the economy, but made inadequate improvements to health services. Health institutions mainly rely on their service revenue to maintain their operation and expansion (Hsiao, 1995). However, these measures have resulted in two serious problems of over-service and escalation of expenditures. The cooperative relationship of the original rural three-tier health network became a competitive one. County hospitals are overflowing, while township health centers turn out to be deserted. Village clinics earn a profit by selling medicine to local residents. On the other hand, the rural cooperative medical system (known as CMS) had twists and turns with the shrinkage of government support. Local residents mainly pay for services out of pocket. The issue of affordability and accessibility to medical care service is severe. After SARS, the Chinese government put forward a plan to coordinate the requirements of health development.

In 2003, a new rural cooperative medical system was established (NCMS) and achieved great success. Different from the traditional rural cooperative medical system, the government plays a major role both in finance and medical management. By 2015, the individual premium and government contribution has reached $¥ 500 \mathrm{RMB}$, which the government grants $3 / 4$ of the total. The new rural cooperative medical fund has become the main source of health institutions' revenue, as the coverage reached over $95 \%$ of the population. In recent years, 
health reform has mainly focused on the adjustment of the hospital drug retailing markup policy and the price of medical services. Hospital operating mechanisms changed gradually as did people's expectations. Large hospitals operated in silos and competed for high-tech and scale of hospital beds. Patients sought medical care outside the county. The small hospitals suffered from poor technical skills and non-standard services. Technical assistance from the superior hospital is not firm or effective and lacks any sustainability. The problem of village doctors is even more prominent with the aging of knowledge capacity, with some places not having a village doctor at all.

At the same time, the demand for health services grew rapidly, chronic diseases rose, and the introduction of new medical technology influenced the rapid escalation of health expenditures, causing a huge threat to health insurance. The urgent needs force insurance to contain costs, but also strengthen prevention and change people's unhealthy behaviors to make the health system sustainable.

\section{Achievements}

Anhui CIHO innovative reform, launched in 2015, gradually showed its vigor and vitality and also received widespread concern and appreciation from society.

$\mathrm{CIHO}$ solves the issue related to affordability and accessibility to medical care service for local residents in Anhui province. In 2016, compared with non-pilot counties, the cost of hospitalization in the pilot counties dropped from 5985 RMB to $5727 \mathrm{RMB}$ and the total cost was reduced 782 million RMB, alleviating the burden of personal out of pocket expenses of 297 million RMB. Through the implementation of clinical pathway management measures, medical disputes decreased significantly, the doctor-patient relationship improved, and public satisfaction increased to more than $90 \%$. The absolute amount of inpatient costs have decreased. The patients' burden has been eased. Compared with non-pilot counties, it was reduced 258 RMB between 2015 and 2016. Thus, the NCMS reimbursement ratio is about $10 \%$ higher. Meanwhile, more local residents staying in the county seeking medical treatment, and NCMS funds have become more secure and stable.

Another major achievement is the recognition of health prevention. A typical example is that, in an elderly populated village of Jiapeng in Funan county, 326 people are over 65 years old, half of whom suffering from hypertension, hyperlipidemia, and diabetes mellitus. When winter comes, there are dozens of people suffering from cerebral infarction with hospitalization. The associated medical expense costs tens of thousands. There are also several people who suffer from long-term paralysis. After the initiative launched, village doctors provided contracted services with local residents. 150 residents were involved in the contracted Jiapeng village clinics program. According to the service norm, the village doctors regularly take blood pressure, measure electrocardiograms, convince residents to develop a reasonable diet and take their medicine on time. Last year, only one elderly citizen was hospitalized due to cerebral infarction therefore saving NCMS funds. CIHO awarded Jiapeng village clinics 30 thou- 
sand $\mathrm{RMB}$, and village doctors used a few thousand to buy some of the daily testing instruments and drugs, provided free to the residents.

The most important change after CIHO was initiated, is the shift in health care philosophy from clinical care to prevention and curation, from generating more revenue by providing more curative care to containing cost by providing more preventive care to residents. Tianchang People's Hospital gives each patient double prescriptions; one is a common prescription and the other is a healthy behavior prescription (which are advice concerning illness-related issues). It helps strengthen the management of chronic diseases and reduce mobility. In addition, CIHO leading institutes now refer their professionals actively and frequently to township health centers, and provide clinical guidance to local doctors, instead of relying on administrative orders as in the past. Clinical assistance is an extremely important tool for reinstalling the referral system; Zhang Hang is one of the beneficiaries of this change.

In the CIHO initiative, village doctors become gatekeepers for both the health of the residents and the NCMS funds, are the health information advocates, managers, and hospital care navigators. The new order of seeking care is first at township health centers and village clinics. A two-way referral system has begun to be accepted widely as has transforming the NCMS from hospital-based care insurance to all health care insurance.

\section{Prospect}

"CIHO as a system focus on solving the existing problems, adopted the financial leverage of health insurance payment to promote the cooperation and formation of responsibility sharing, benefit sharing, promoting people health centered, win-win development among healthcare institutes in the county". The statement is within a document from the Provincial Health and Family Planning Commission in Anhui province. CIHO is aimed at providing seamless and sustainable life-span healthcare. CIHO initiative is Chinese contemporary primary health care (CPHC), or upgraded primary health care (UPHC) (Cohen et al., 2010). In next stage, CIHO will expand to other health insurance and national essential public services package funds as prepaid capitation, thus strengthening the impulse to build up CIHO structures, accelerate the transformation of health care patterns, effectively cope with the challenges of aging and chronic diseases, and improve the quality of care. Studying Anhui CIHO initiative, there are many similarities with the models of HMO (Health Maintenance Organization) and IDS (Integrated Delivery System) in the United States, especially the Kaiser Permanente model.

World Bank recently joined with WHO and carried out an important study on China health reform. They proposed people-centered integrated care, aimed at confronting aging and providing excellent patient satisfaction (Klein, 2011). Coincidently with this health reform suggestion, Anhui CIHO is at its preliminary exploration in China, having characteristics of being patient-centered and having innovative healthcare networks designed healthcare delivery congruent 
with patients' needs which tailor the offerings to patients' expectations.

World Bank Group President, Jim Yong Kim, highly praised the practice of this Anhui CIHO initiative when visiting Tianchang. He illustrated that the reform is going to take all over China, and there is going to be helpful for just about every country in the world. So Anhui will be the model for the rest of the world.

In August 2016, the Chinese government held the national health conference, and Xi Jinping, Chairman of China, put forward the goal of Healthy China and called for efforts to provide people with life-span health care. Anhui CIHO is likely to be one of the most promising health care solutions to achieve the Healthy China goal.

\section{References}

Cohen, J. R., Gerrish, W., \& Galvin, J. R. (2010). Health Care Reform and Connecticut's Non-Profit Hospitals. Journal of Health Care Finance, 37, 1-7.

Hsiao, W. C. (1995). The Chinese Health Care System: Lessons for Other Nations. Social Science \& Medicine, 41, 1047-1055. https://doi.org/10.1016/0277-9536(94)00421-O

Klein, S. (2011). The Veterans Health Administration: Implementing Patient-Centered Medical Homes in the Nation's Largest Integrated Delivery System.

Stuart, B., \& Zacker, C. (1999). Who Bears the Burden of Medicaid Drug Copayment Policies? Health Affairs, 18, 201-212. https://doi.org/10.1377/hlthaff.18.2.201

Tobe, M., Stickley, A., Jr, R. B. R., \& Shibuya, K. (2013). Out-of-Pocket Medical Expenses for Inpatient Care among Beneficiaries of the National Health Insurance Program in the Philippines. Health Policy and Planning, 28, 536-548.

https://doi.org/10.1093/heapol/czs092

Submit or recommend next manuscript to SCIRP and we will provide best service for you:

Accepting pre-submission inquiries through Email, Facebook, LinkedIn, Twitter, etc. A wide selection of journals (inclusive of 9 subjects, more than 200 journals)

Providing 24-hour high-quality service

User-friendly online submission system

Fair and swift peer-review system

Efficient typesetting and proofreading procedure

Display of the result of downloads and visits, as well as the number of cited articles

Maximum dissemination of your research work

Submit your manuscript at: http://papersubmission.scirp.org/

Or contact chnstd@scirp.org 